\title{
Erratum to: Finding protein thermostability and spin-coupling constant using Bayesian statistics
}

\author{
Wenjin Zhou • Allison M. Rossetto
}

Published online: 4 December 2014

(C) Springer International Publishing Switzerland 2014

\section{Erratum to: J Math Chem \\ DOI 10.1007/s10910-014-0416-z}

A correct version of Fig. 5 is presented here to correct errors in the originally published version.

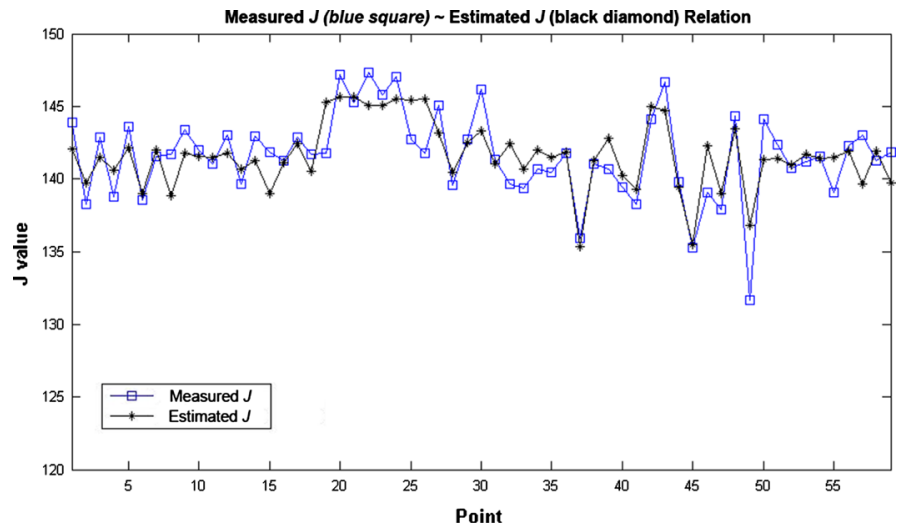

Fig. 5 Measured spin-coupling constant J (blue open square) and estimated J (black filled diamond) values generated using MATLAB

The online version of the original article can be found under doi:10.1007/s10910-014-0416-z.

\section{W. Zhou $(\varangle) \cdot$ A. M. Rossetto}

Department of Computer Science and Engineering, Oakland University, Rochester, MI 48309-4401, USA

e-mail:wzhou@oakland.edu
A. M. Rossetto
e-mail: amrosset@oakland.edu 